\title{
TITLE:
}

\section{$<$ News> "Kyoto Declaration on Great Apes" has been Adopted}

AUTHOR(S):

Nishida, Toshisada

CITATION:

Nishida, Toshisada. < News> "Kyoto Declaration on Great Apes" has been Adopted. Pan Africa News 2004, 11(2): 2-3

ISSUE DATE:

2004-12

URL:

http://hdl.handle.net/2433/143446

RIGHT:

Copyright (C) Pan Africa News. 


\section{<NEWS>}

\section{"Kyoto Declaration on Great Apes" has been Adopted}

\section{Toshisada Nishida}

Japan Monkey Centre

The international symposium titled "African Great Apes: Evolution, Diversity and Conservation" was held in Kyoto from $3-5$ March 2004. This international conference forms a part of the $21^{\text {st }}$ Century COE Program (A14) "Formation of a Strategic Base for the Multidisciplinary Study of Biodiversity" funded by the Ministry of Education, Culture, Sports, Science and Technology. The symposium was organized by myself with Prof. Juichi Yamagiwa as the Secretary-General and Dr. Shigeru Suzuki as the Leader of the Task Force. The symposium was opened at 13:00 pm, starting with poster presentation and welcome party at the Kyoto Garden Palace Hotel where invited speakers were staying. For the following two days, the venue was moved to KyodaiKaikan where oral presentations were given by 21 invited speakers. It was divided into six sessions; (1) Behavioral Diversity and Origins of Human Culture, (2) Sympatry and Coexistence of African Great Apes, (3) Natural
Environments and Evolution of African Great Apes, (4) The Significance of Pan Social Behavior, (5) Contributions of African Great Apes to Biodiversity, (6) Great Apes as the World Heritage Species. Please check the homepage of the $21^{\text {st }}$ Century COE program (http://ethol. zool.kyoto-u.ac.jp/coe/coe.htm) for detail. I reported the establishment of GRASP-Japan in which Japanese researchers of the great apes cooperate in saving them from the brink of extinction. The Kyoto declaration on great apes was also adopted. Several members including Dr. John Oats, Dr. Richard Wrangham and myself prepared the draft (see [Column 1]). Sixtynine participants including all field researchers of great apes present signed for this declaration. Names of signatories are listed in the [Column 2].

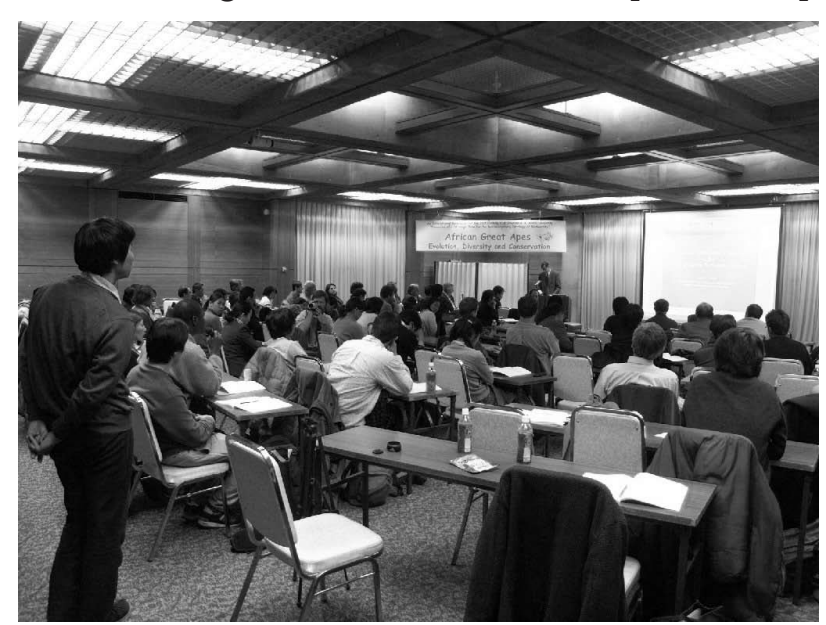

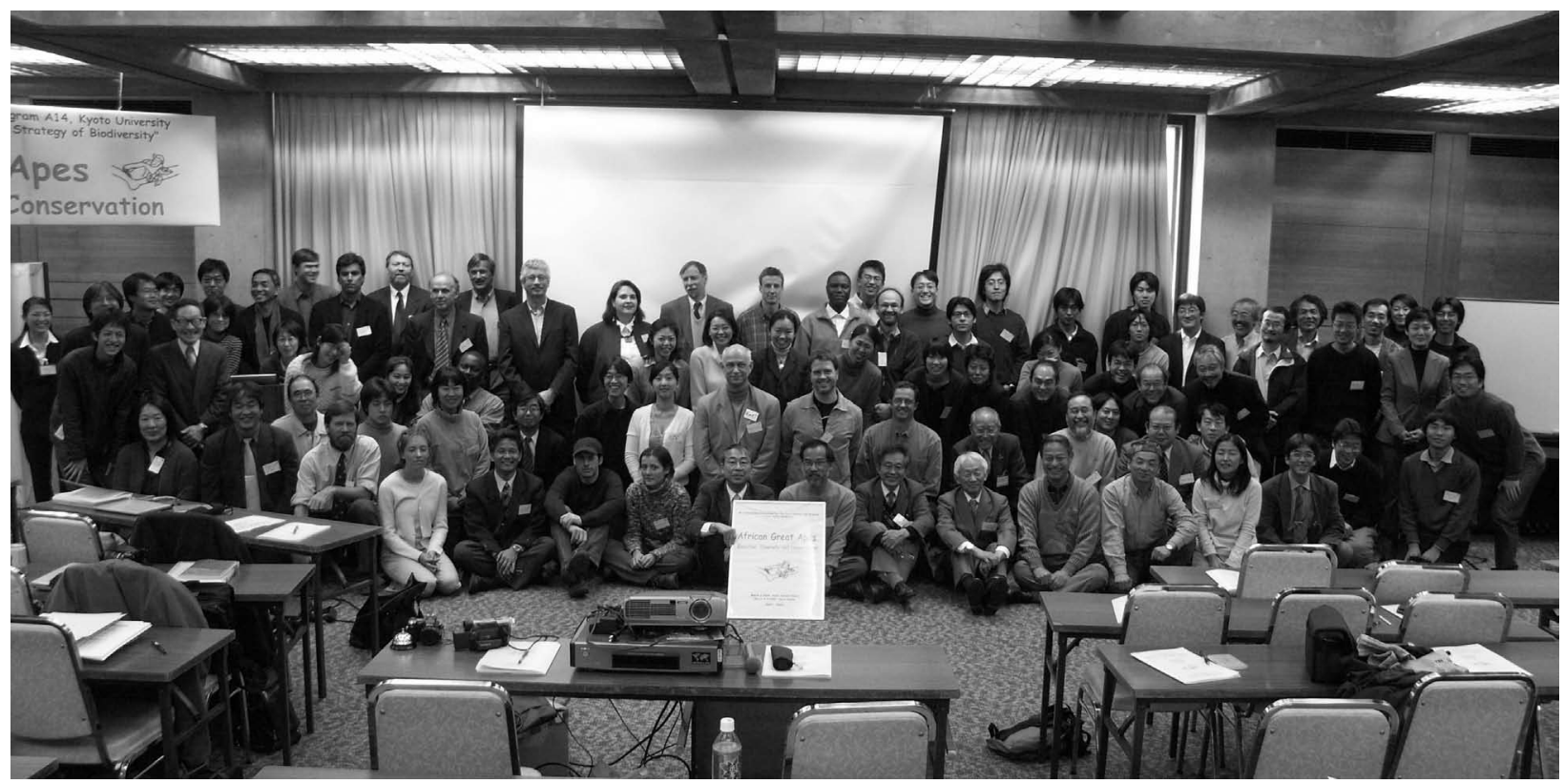


[Column 1] Kyoto Declaration on

Great Apes (Kyoto, March 5, 2004)

As a participant in this symposium, I agree with the following statement to promote conservation efforts for the great apes. 1. The international scientists assembled in Kyoto agreed that many populations of great apes (humans' closest living relatives) are now very seriously endangered with extinction and that their numbers continue to decline.

2. As scientists studying great apes (Chimpanzees, Bonobos, Gorillas and Orangutans), we feel a special responsibility to address this issue.

3. We urge that the people and governments of ape-range and non-range countries work together to improve the conservation of the great apes and their natural habitats.

[Column 2]: List of signatories

( i n a l p h a b e t i c a l o r d e r) Kaoru ADACHI, Yoko AKARI, Karl AMMAN, Dean P ANDERSON, Tamotsu AOKI, A Basabose KANYUNYI, Juliane BRAUER, Takisato DO, Sarah DUNPHY-CELLI, Tomoo ENOMOTO, Shiho FUJITA, Fumio FUKUDA, Takeo FUNABIKI, Takeshi FURUICHI, Miya HAMAI, Chie Hashimoto, Shuhei HAYAISHI, Kazuhiko HOSAKA, Michael A HUFFMAN, Kevin D HUNT, Gen-ichi IDANI, Yumi IKEDA, Agumi INABA, Noriko ITOH, Mitsuo IWAMOTO, Naomi KAWAGUCHI, Yuichiro KITAYAMA, Mieko KIYONO, Nobuyuki KUTSUKAKE, Takeshi KOBAYASHI, Suehisa KURODA, Tamaki MARUHASHI, Miki MATSUBARA, Akiko MATSUMOTO, William C McGREW, John MITANI, Akio MORI, Miho NAKAMURA, Masato NAKATSUKASA, Toshisada NISHIDA, Tuyoshi NISHIMURA, John F OATES, Gaku OOHASHI, Andrew J PLUMPTRE, Melissa J REMIS, Naruya SAITO, Masaki SHIMADA, Yukiko SHIMOOKA, David SPRAGUE, Craig STANFORD, Kazusa SUGAYA, Yukimaru SUGIYAMA, Akira SUZUKI, Tetsuya SUZUKI, Yukio TAKAHATA, Yuji TAKENOSHITA, Chihiro TANAKA, Ichiro TANAKA, Yasuko TASHIRO, Sayaka TUTUMI, Frans de WAAL, Mikihiko WADA, James V WAKIBARA, Roman WITTIG, Richard WRANGHAM, Juichi YAMAGIWA, Shin-ya YAMAMOTO, Shin-ichi YOSHIHIRO, Koichiro ZAMMA 